\title{
1 Virus-like particles (VLPs) are efficient tools for 2 boosting mRNA-induced antibodies
}

3 Anne-Cathrine S. Vogt ${ }^{1,2}$, Lukas Jörg ${ }^{3,4}$, Byron Martina ${ }^{5,6}$, Pascal S. Krenger ${ }^{1,2}$, Xinyue

4 Chang $^{1,2}$, Andris Zeltins ${ }^{7}$, Monique Vogel ${ }^{1,2}$, Mona O. Mohsen ${ }^{1,2 *}$ and Martin F. Bachmann ${ }^{1,2,8 *}$ 5

6 Affiliations:

71 Department of Rheumatology and Immunology, University Hospital, Bern, 3010 Bern,

$8 \quad$ Switzerland

92 Department of BioMedical Research, University of Bern, 3008 Bern, Switzerland

$10{ }^{3}$ Division of Allergology and Clinical Immunology, Department of Pneumology, Inselspital,

11 Bern University Hospital, University of Bern, 3010 Bern, Switzerland

$12{ }^{4}$ Allergy Unit, Department of Dermatology, University Hospital of Zurich, 8091 Zurich,

13 Switzerland

$14{ }^{5}$ Erasmus Medical Center, department of Viroscience, Rotterdam, The Netherlands

$15{ }^{6}$ Artemis Bio-Support, Delft, The Netherlands

$16{ }^{7}$ Latvian Biomedical Research \& Study Centre, Ratsupites iela1, Riga, LV 1067, Latvia

$17{ }^{8}$ Nuffield Department of Medicine, Centre for Cellular and Molecular Physiology (CCMP), The

18 Jenner Institute, University of Oxford, Oxford, UK

19

$20 *$ equal contribution

21 Corresponding authors: Anne-Cathrine S. Vogt: anne-cathrine.vogt@students.unibe.ch Mona O. Mohsen: mona.mohsen@dbmr.unibe.ch

Short title: Heterologous prime-boost strategies based on mRNA and VLPs

Key words: COVID-19, SARS-CoV-2, vaccine, virus-like particles, mRNA 


\section{Abstract}

mRNA based vaccines against COVID-19 have proven most successful at keeping the SARS-

CoV-2 pandemic at bay in many countries. Recently, there is an increased interest in heterologous prime-boost vaccination strategies for COVID-19 to maintain antibody response for the control of continuously emerging SARS-CoV-2 variants of concern (VoCs) and to overcome other obstacles such as supply shortage, costs and reduced safety issues or inadequate induced immune-response. In this study, we investigate the antibody responses induced by heterologous prime-boost with vaccines based on mRNA and virus-like particles (VLPs). The VLP-based $\mathrm{mCuMV}_{\mathrm{TT}}-\mathrm{RBM}$ vaccine candidate and the approved mRNA-1273 vaccine were used for this purpose. We find that homologous prime boost regimens with either mRNA or VLP induced high levels of high avidity antibodies. Optimal antibody responses were, however, induced by heterologous regimens both for priming with mRNA and boosting with VLP and vice versa, priming with VLP and boosting with mRNA. Thus, heterologous prime boost strategies may be able to optimize efficacy and economics of novel vaccine strategies.

\section{Introduction}

Multiple immunizations are usually required for most vaccines to be successful in protecting against a virus and its emerging variants. For instance, five-dose series of Tetanus, Pertussis and Diphtheria (DTaP) vaccine is required during childhood and an adolescent booster dose to elucidate the aimed protection (1). It is not entirely clear why some vaccines require more additional boosters than others; however, it is well accepted that multiple immunizations are essentials for better response, in particular for non-replicating vaccines (2). An annual dose of influenza vaccine is also recommended for persons who may be at increased risk for complications from influenza infections.

Additionally, heterologous prime-boost regimens in particular when using vectored vaccines have previously shown better immunogenicity; for example, priming with e.g. DNA and boosting with e.g. viral vectors $(3,4)$. The need to change the vector may be explained 
by the induction of neutralizing antibodies against the vector, which compromise further boosting with the same vector. Vaccine-specific antibodies have also been reported to suppress the cytotoxic (CTL) response when using the non-infectious virus-like particles

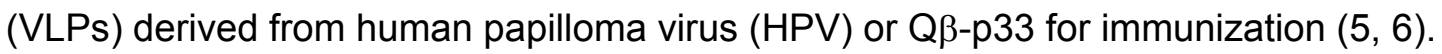
countries have prioritized the development of SARS-CoV-2 vaccine to contain the virus. Currently, 8 vaccines are approved in various countries and around 60 vaccines are in clinical development, of which 13 are in phase $3(7)$. Several leading vaccines have been shown to confer protection and induction of neutralizing antibodies against the wild type SARS-CoV-2. However, with the continuous emergence of SARS-CoV-2 variants and the drop in antibody titers induced in vaccinated individuals, serious concerns are raised by public health organizations concerning the duration and efficacy of antibody responses by current vaccines (8).

Next-generation COVID-19 vaccines which have been approved for emergency use, namely mRNA vaccines such as BNT162b2 and mRNA-1273, have their own advantages and disadvantages. Obviously, the main advantage is their remarkable efficacy of $95 \%$ for Pfizer ${ }^{\circledR}$ mRNA vaccine and $94.1 \%$ for Moderna ${ }^{\circledR}(9,10)$. On the other hand, their adverse reactions profile has raised concerns with respect to their safety profile. The incidence of local and systemic adverse reactions (AR) has been shown to be relatively high for mRNA and adenovirus-based vaccines with Local AR reaching 40\%-88.9\% and systemic AR between $44 \%$ and $86 \%$, respectively (11).

Virus-like particles (VLPs) are considered traditional vaccine platforms. They are virusderived structures and have the ability self-assemble to mimic the parental virus in size and shape. One important aspect is that VLPs lack any genetic materials; accordingly, they are not capable of infecting the host cell or replication (12). Such traditional VLP-based vaccines have been approved for human use against different viruses decades ago. For example, vaccines against Hepatitis $B$ and E viruses (HBV and HEV), Human Papilloma Virus (HPV) and the newly developed malaria vaccine (13). VLP-based vaccines have also been tested 
83 for COVID-19 in preclinical and clinical trials. The traditional vaccine platforms have shown

84 lower incidence of adverse side effects (14); however they typically also showed inferior

85 immunogenicity in comparison to the next-generation mRNA vaccines $(15,16)$.

86 In line with the above, heterologous prime-boost vaccination strategies using different

87 vectors should be tested to elicit broader and more efficient protective immune-responses with better and improved safety profiles. This strategy may meet the emergency needs in the current pandemic. In the current study, we evaluated different prime and boost regimens combining mRNA-1273 with a VLP-based vaccine based, namely mCuMV $\mathrm{TT}_{\mathrm{T}}-\mathrm{RBM}$. We have previously designed and developed the scalable and immunogenic VLP-based COVID-19 vaccine $m C u M V_{T T}-R B M$, which has been shown to induce $R B D$-specific $\lg$ and $\lg A$ antibodies with strong neutralizing capability, albeit inferior to mRNA induced response (15).

We show that a booster dose with mRNA-1273 or $\mathrm{mCuMV}_{\mathrm{TT}}-\mathrm{RBM}$ induced high levels of high avidity antibodies. Interestingly, highest antibody responses were measured, when vaccination was performed by heterologous administration of mRNA for prime and VLP as boost and vice versa, priming with VLP and boosting with mRNA. Along these findings, heterologous prime boost strategies may be able to improve efficacy and economics of current vaccine protocols. 


\section{Results}

102 2.1. Heterologous prime-boost vaccine administration 103 induces comparable high levels of RBD-specific antibodies 104 following the booster dose

We have designed different heterologous vaccination regimens using mRNA-1273 vaccine

106 (Moderna $^{\circledR}$ ) and our newly developed mosaic COVID-19 VLPs-based vaccine mCuMV $\mathrm{TT}_{\mathrm{T}}-\mathrm{RBM}$

107 (15) as illustrated in Figure 1A. For SARS-CoV-2 specific vaccine, the mRNA provides the 108 genetic expression of the spike protein of COVID-19 (17). The mRNA of the spike protein is 109 then translated by the host, thus allowing the host to mount an antibody response against the 110 expressed protein $(18,19)$. mRNA-1273 has shown $>90 \%$ effectiveness in preventing the 111 SARS-CoV-2 infection, at least for the original Wuhan strain (10). mCuMV $\mathrm{TT}_{\mathrm{T}}$ RBM is a plant112 derived VLPs which incorporates the receptor-binding motif (RBM) of SARS-CoV-2 using 113 genetic fusion techniques. $\mathrm{mCuMV}_{\mathrm{TT}}-\mathrm{RBM}$ also incorporates in its interior surface a tetanus 114 toxin (TT) epitope which is believed to enhance the immune response in elderly people. 115 Specifically, the TT-epitope is expected to augment the interaction between TT-specific T 116 helper $\left(T_{H}\right)$ cells and RMB-specific $B$ cells. This is supported by the fact that pre-existing 117 immunity to the chosen TT epitope is very broad in humans (and animals) as the peptide binds essentially to all HLA-DR molecules and most people have been immunized many times 119 against TT. Additionally, mCuMV $\mathrm{TT}_{\mathrm{T}}-\mathrm{RBM}$ is packaged with ssRNA, a TLR7/8 ligand and serves 120 as a natural adjuvant $(20,21)$. $10 \mu \mathrm{g} / \mathrm{dose}$ of mRNA-1723 vaccine and $100 \mu \mathrm{g} / \mathrm{dose}$ of $\mathrm{mCuMV}_{\mathrm{TT}}-\mathrm{RBM}$ were used in 122 this experiment for priming and boosting. Balb/c mice were divided into two groups for 123 subcutaneous (s.c.) priming with mRNA-1723 or mCuMV $\mathrm{TT}_{\mathrm{T}}-\mathrm{RBM}$ vaccines (Fig. 1A). Blood 124 samples were collected on a weekly basis to measure the induced RBD-specific antibodies by ELISA. Our results showed successful induction of RBD-specific antibodies 7 days after subcutaneous injection of mRNA-1723 or $\mathrm{mCuMV}_{\mathrm{TT}}-\mathrm{RBM}$ (Fig. 1B). mRNA-1723 was 
127 superior to $\mathrm{mCuMV}_{\mathrm{TT}}-\mathrm{RBM}$ in inducing RBD-specific antibodies measured on days 7, 14 and

12821 (Fig.1C-G) but the VLPs also was effective at inducing rapid IgG responses.

The primed mice were divided next into four groups (Fig. 1A) and received a booster

130 dose on day 21 using mRNA-1723 or mCuMV $\mathrm{TT}_{\mathrm{T}}-\mathrm{RBM}$. Therefore, mice are grouped and

131 immunized as follows: Group I (mRNA-1723 $\rightarrow$ mRNA-1723), Group II (mRNA-1723 $\rightarrow$

$\left.\mathrm{mCuMV}_{\mathrm{TT}}-\mathrm{RBM}\right)$, Group III $\left(\mathrm{mCuMV}_{\mathrm{TT}}-\mathrm{RBM} \rightarrow \mathrm{mCuMV}_{\mathrm{TT}}-\mathrm{RBM}\right)$ and Group IV (mCuMV $\mathrm{TT}^{-}$

$133 \mathrm{RBM} \rightarrow \mathrm{mRNA}-1723$ ). Blood samples were collected on days 28 and 35 to measure the

134 induced RBD-specific antibodies by ELISA. Interestingly, heterologous boost with mRNA-

1351723 or $\mathrm{mCuMV}_{\mathrm{TT}}-\mathrm{RBM}$ showed a similar induction of RBD-specific antibodies with no

136 statistical difference for sera collected on days 28, 35 and 42 (Fig. $1 \mathrm{H}-\mathrm{K}$ ). This demonstrates

137 that $\mathrm{mCuMV}_{\mathrm{TT}}-\mathrm{RBM}$ can significantly boost previously primed B-cells to a similar titer when

138 using a homologous mRNA vaccine.

2.2. A second booster dose further enhances the induced immune response

Taking into account the slightly inferior immunogenicity of $\mathrm{mCuMV}_{\mathrm{TT}}-\mathrm{RBM}$ vaccine to mRNA1723, and our previous data showing that a $2^{\text {nd }}$ booster dose of $\mathrm{mCuMV}_{\mathrm{TT}}-\mathrm{RBM}$ would enhance the quality of the induced antibodies (15), a $2^{\text {nd }}$ booster dose was performed on day 56 in Groups II, III and IV as illustrated in Figure 2A. As Group I represents the standard immunization strategy followed in almost all countries, no booster dose was applied. ELISA data for OD450 and OD50 for days 63 and 70 did not show an increase in RBD-specific antibodies in comparison to the induced antibodies following the $1^{\text {st }}$ boost (Fig. 2B -D).

The avidity of the induced antibodies was assessed using a modified immunoassay using $7 \mathrm{M}$ urea which facilitates the detachment of the low avidity antibodies. More specifically,

151 we compared the avidity of RBD-specific antibodies on days 42 and 70, i.e. after 2 or 3 152 injections. For group I, which was primed and boosted with mRNA-1723, the avidity of RBD153 specific antibodies didn't differ on days 42 and 70 (p. 0.7460). In Group II (which received a 154 prime with mRNA-1723 and 2 booster doses of $\left.\mathrm{mCuMV}_{\mathrm{TT}}-\mathrm{RBM}\right) \sim 80 \%$ of RBD-specific 
antibodies were of high avidity after the $1^{\text {st }}$ boost in comparison to $\sim 90 \%$ following the 2 nd

156 booster dose (p. 0.0436). This finding was similar in group IV (which received a prime with

157 mCuMV $\mathrm{TT}_{\mathrm{T}}-\mathrm{RBM}$, followed by a $1^{\text {st }}$ boost with mRNA-1723 and $2^{\text {nd }}$ boost with $\mathrm{mCuMV} \mathrm{TT}_{\mathrm{TT}}-\mathrm{RBM}$ ),

158 again with statistically significant difference in avidity between day 42 and 70 (p. 0.0243) (Fig.

$1592 \mathrm{~F})$. The induction of higher avidity antibodies following 3 vaccinations with $\mathrm{mCuMV} \mathrm{TT}_{\mathrm{T}}-\mathrm{RBM}$ is consistent with our previous findings (15).

It was also of interest to study the longevity of the induced antibodies after vaccination

162 with the different heterologous strategies. Accordingly, we have tested RBD-specific 163 antibodies up to 5 months after the priming dose. The results revealed a slight drop in the 164 antibody titer in group I (received 2 doses of mRNA-1723), however was not significantly different when compared to the other groups. Groups II, III and IV showed a stable antibody titer comparable to the titers seen on days 42 and 70 (Fig. $2 \mathrm{G}$ and $\mathrm{H}$ ).

\subsection{The induced antibodies recognize SARS-CoV-2} variants of concern (VoCs) efficiently

170 To test the capacity of the induced antibodies following the heterologous prime-boost regimen

171 to neutralize SARS-CoV-2 wild-type and its mutated delta variant, we used a reduction of cytopathic effect (CPE) assay. $100 \mathrm{TCID}_{50}$ of SARS-CoV-2/ABS/NL20 or delta strain have been used and titers have been expressed as the highest dilution that inhibits $50 \%$ CPE formation. No significant difference was detected between the four groups when measuring the neutralization titer against SARS-CoV-2 wild-type (Fig.3A). When comparing the induced neutralization titer against the delta $\mathrm{VoC}$, our results show a significant difference between

177 Group I (2xRNA) and III (3xVLP) (p. 0.039) confirming the superiority of mRNA only over VLPonly based vaccines. However, no statistical differences have been detected between Group I and II (p. 0.2558) or between Group I and IV ( $p>0.999)$ (Fig. 3B). This indicates that mRNA may be used to boost VLP-induced antibody responses; or vice versa, and probably more

181 importantly, VLPs may be used to boost RNA-induced responses. Hence, classical VLP-

182 based vaccines may be used to boost mRNA induced antibody responses. 
183

\section{4}

185

186

187

\section{Discussion}

The highly contagious SARS-CoV-2 virus has put a heavy toll on the world's public health systems and caused a disruption of the world economy (22). The use of masks, physical distancing, contact tracing as well as isolation of sick or infected people are important but insufficient measures to reduce the spread of the corona virus disease (23). Accordingly, vaccine campaigns are needed to curb the spread of SARS-CoV-2 and thereby reducing the mortality and morbidity associated with the disease.

The commercially available mRNA vaccines require stringent storage conditions during transport and at vaccination sites as they have a short half-life (24). According to manufactures information, mRNA-1273 is stable up o 6 month when kept at $-20^{\circ} \mathrm{C}$, whereas to store BNT162b2 for the same time-period, temperatures between $-80^{\circ} \mathrm{C}$ to $-60^{\circ} \mathrm{C}$ are needed $.9,10$ With regard to stability at room temperature, mRNA-1273 is stable for up to $12 \mathrm{~h}$; in contrast BNT162b2 has to be administered within 6h after thawing (25). These strict storage conditions represent a major obstacle for efficient use in less affluent parts of the world. Beside the challenging storage conditions, a further obstacle represent the production-costs of RNAbased vaccines, limiting their global access. BNT162b2 has a production cost of $\$ 19.50$ and mRNA-1273 with even higher costs at $\$ 32-37(11,26)$. This can cause a major problem in low-income countries, to afford these types of vaccines. Therefore, cost effective and efficient vaccine candidates are of high importance taking into account the continuous persistence of the virus and the obstacles in eradicating it worldwide. We have previously shown high stability of our newly developed VLP-based vaccine-candidate $\mathrm{mCuMV}_{T T}-\mathrm{RBM}$ which was stable for at least 14 months at $4^{\circ} \mathrm{C}$ without signs of degradation (15). This has also been confirmed with other preclinical studies showing the stability of $\mathrm{mCuMV}_{T T}$-based vaccines for up to 12 months when kept at $4^{\circ} \mathrm{C}$. Thus indicating a significant advantage for such VLP-based vaccines (27). Additionally, the production of $\mathrm{mCuMV}_{T T}-\mathrm{RBM}$ is highly scalable allowing the production of millions of the doses in a single $1000 \mathrm{~L}$ fermenter run (15). The rapid pace of mRNA vaccine 
bioRxiv preprint doi: https://doi.org/10.1101/2021.12.20.473421; this version posted December 22,2021 . The copyright holder for this preprint (which was not certified by peer review) is the author/funder, who has granted bioRxiv a license to display the preprint in perpetuity. It is made available under aCC-BY 4.0 International license.

211 development accompanied fears of potential long-term adverse effects have raised some

212 concerns in global community. VLP-based vaccines are therefore of high interest as they

213 display a safe platform, due to the lack of replicating genetic material which is also been

214 confirmed in the approved and marketed vaccines (HBV-HEV-HPV and recently Mosquirix ${ }^{\mathrm{TM}}$ )

215 (13). In addition, the here employed mCuMV $_{\mathrm{TT}}$ technology does not need use of an adjuvant.

216 Our data show that both vaccine-types, mRNA-1723 and mCuMV $\mathrm{TT}_{\mathrm{T}}-\mathrm{RBM}$ are capable

217 of inducing high RBD-specific antibody titers 7 days following the priming dose. Interestingly,

218 mRNA-1723 shows a superior induction of antibody response in comparison to the VLP-based

219 vaccine. However, after the administration of the $1^{\text {st }}$ homologous boosting, this difference was

220 not statistically significant anymore (Group I and III). The same was true heterologous boosts

221 (Group II and IV), indicating the ability of VLPs to efficiently boost the B cells primed by mRNA.

222 We have previously hypothesized that natural infection with SARS-CoV-2 virus induces short-

223 lived neutralizing antibodies due to the unusually large distance between RBD-epitopes

224 embedded in the membrane surface (28). This obstacle may be overcome by grafting RBM or

225 RBD onto highly repetitive nanoparticles such as the here used mCuMV $\mathrm{TT}_{\mathrm{T}}$ VLPs, resulting in

226 successful display of the virus-epitopes at optimal distances of $5-10 \mathrm{~nm}$. This pathogen-

227 associated structural pattern (PASP) may also play a role in the induction of higher avidity

228 antibodies as shown after the $2^{\text {nd }}$ booster dose.

229 With the continuous emergence of SARS-CoV-2 variants (VoCs), it may be essential

230 to administer repetitive booster doses, as higher antibody levels may need to be maintained

231 for sustained protection. Indeed, our data demonstrate that a $2^{\text {nd }}$ boost can maintain antibody

232 titers. Furthermore, the $2^{\text {nd }}$ boost in the different heterologous regimens in groups II, III and IV

233 have significantly enhanced the avidity of the antibodies, likely a key attribute for neutralization

234 of emerging new variants.

235 The neutralizing capacity of the induced antibodies following the homologous or 236 heterologous vaccination strategies showed that both approaches are efficient against the 237 wild-type SARS-CoV-2. No statistical difference in the ability to neutralize the delta variant has 238 been detected between groups I, II and IV. Furthermore, heterologous boosting of mice primed 
239 with mRNA-1723 or $\mathrm{mCuMV}_{\mathrm{TT}}-\mathrm{RBM}$ revealed similar outcome. These data confirm the ability

240 of $\mathrm{mCuMV}_{\mathrm{TT}}-\mathrm{RBM}$ to efficiently boost antibodies primed with mRNA-1723 vaccine in a similar

241 way to the standard followed vaccination strategy (mRNA-1723 prime/ boost).

242 Collectively, our data support the premise of using a heterologous prime/boost

243 vaccination regimen against COVID-19. The CuMV $\mathrm{TT}^{-R B M}$ VLPs may therefore constitute an

244 efficient platform for boosting previously primed B cell responses; here we demonstrate this

245 for mRNA primed responses, but it is likely that this may extend to B cell responses primed by

246 other modalities, including vector- or virus induced immune reactions.

247

248

249

250

251 


\section{4. Materials and Methods}

253

254

255

256

257

258

259

260

261

262

263

264

265

266

267

268

269

270

271

272

273

\subsection{Mice}

In vivo experiments were performed using 8-12 weeks-old female, BALB/cOlaHsd mice purchased from Envigo (Amsterdam, Netherlands). All mice were maintained in microisolater cages with free access to water and food. Mice were kept on standard chow diet ((diet Catalog \# 3430); Granovit AG-Kliba Nafag, Switzerland). All animals could acclimatize to the facility for one week before experiments were performed. All animal procedures were conducted in accordance with the Swiss Animal Act (455.109.1 - September 2008, $5^{\text {th }}$ ) of University of Bern. All animals were treated for experimentation according to protocols approved by the Swiss Federal Veterinary Office.

\subsection{Vaccines}

mRNA-1273 (Moderna ${ }^{\circledR}$ ) was kindly provided the Inselspital, Bern University Hospital. Mosaic ( $\left.\mathrm{mCuMV}_{\mathrm{TT}}-\mathrm{RBM}\right)$ vaccine was prepared as previously described by Mohsen et al. (15).

\subsection{Vaccination regimen/dose/sera collection}

Wild type BALB/cOlaHsd mice were vaccinated subcutaneously (s.c.) using different regimens as summarized in Table 1. 10 $\mu \mathrm{g}$ (Prime on day 0 ) and $10 \mu \mathrm{g}$ for a booster dose on day 21 were used. $\mathrm{mCuMV} \mathrm{TT}_{\mathrm{T}}-\mathrm{RBM}$ vaccine and $\mathrm{mRNA}-1273$ were diluted in $1 \mathrm{xPBS}$ in a final volume of $100 \mu \mathrm{l}$ for final injection. Serum was collected on a weekly basis. The three doses regimen (prime- $1^{\text {st }}$ boost- $2^{\text {nd }}$ boost) was either $10 \mu \mathrm{g}$ prime and $100 \mu \mathrm{g} 1^{\text {st }}$ and $2^{\text {nd }}$ boost or $100 \mu \mathrm{g}$ prime and $10 \mu \mathrm{g} 1^{\text {st }}$ boost and $100 \mathrm{mg} 2^{\text {nd }}$ boost given at days 0,21 and 56 .

Table 1: Used Doses and Vaccine Regimens

\begin{tabular}{|c|c|c|}
\hline Dose & Vaccination Regimens & Vaccine \\
\hline $10 \mu \mathrm{g}$ prime/ $10 \mu \mathrm{g}$ boost & D0/D21 & mRNA-1273 (Moderna ${ }^{\circledR}$ ) \\
\hline $100 \mu \mathrm{g}$ prime $/ 100 \mu \mathrm{g} 1^{\text {st }}$ boost $/ 100 \mu \mathrm{g} 2^{\text {nd }}$ boost & D0/D21/D56 & $\mathrm{mCuMV}_{\mathrm{TT}}-\mathrm{RBM}$ \\
\hline $10 \mu \mathrm{g}$ prime $/ 100 \mu \mathrm{g} 1^{\text {st }}$ boost $/ 100 \mu \mathrm{g} 2^{\text {nd }}$ boost & D0/D21/D56 & $\begin{array}{c}\text { Prime: mRNA-1273 } \\
\left.\text { (Moderna }{ }^{\circledR}\right)\end{array}$ \\
\hline
\end{tabular}




\begin{tabular}{|c|c|c|}
\hline & & $\begin{array}{c}1^{\text {st }} \text { and } 2^{\text {nd }} \text { Boost: } \mathrm{mCuMV}_{\mathrm{TT}^{-}} \\
\text {RBM }\end{array}$ \\
\hline $100 \mu \mathrm{g}$ prime $/ 10 \mu \mathrm{g} 1^{\text {st }}$ boost $/ 100 \mu \mathrm{g} 2^{\text {nd }}$ boost & D0/D21/D56 & $\begin{array}{c}\text { Prime: } \mathrm{mCuMV}_{\mathrm{TT}}-\mathrm{RBM} \\
1^{\text {st }} \text { Boost: mRNA-1273 } \\
\left.\text { (Moderna }{ }^{\circledR}\right) \\
2^{\text {nd }} \text { Boost: mCuMV }{ }_{\mathrm{TT}}-\mathrm{RBM}\end{array}$ \\
\hline
\end{tabular}

\subsection{Expression and purification of RBD}

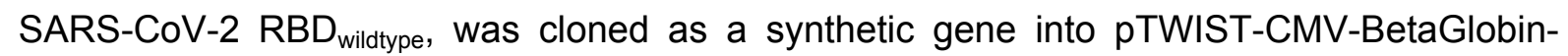
WPRE-Neo vector (Twist Biosciences, CA, USA) and expressed in HEK293F cells through the Expi293 system (ThermoFisher Scientific, MA, USA). Purification was performed by IMAC using a HiTrap TALON crude column (Cytiva, Uppsala, Sweden).

\subsection{Enzyme-linked immunosorbant assay (ELISA)}

282 To determine the total IgG antibodies against the vaccine $m C u M V_{T T}-R B M$ as well as mRNA2831273 in sera of vaccinated mice, ELISA plates (96 well half-area ELISA plates; Costar,

284 Corning, Catalog \# 3690) were coated with SARS-CoV-2 RBD (wildtype) at a concentration of $1 \mu \mathrm{g} / \mathrm{ml}$ overnight at $4^{\circ} \mathrm{C}$. ELISA plates were washed with PBS- $0.01 \%$ Tween and blocked using $100 \mu$ I PBS-Casein $0.15 \%$ for $2 \mathrm{~h}$ in RT. Sera from vaccinated mice was serially diluted $1: 3$ starting with a dilution of $1: 20$ and incubated for $2 \mathrm{~h}$ at RT. After washing with PBS0.01\%Tween, goat anti-mouse IgG conjugated to Horseradish Peroxidase (HRP) (Jackson ImmunoResearch, West Grove, Pennsylvania) was added at 1/1000 and incubated for $1 \mathrm{~h}$ at RT ELISA was developed with tetramethylbenzidine (TMB), stopped by adding equal $1 \mathrm{M}$ H2SO4 solution. OD450 was measured using the SpectraMax M5 ELISA reader (Molecular

292 Devices, Catalog \# M5) and read at $\mathrm{OD}_{450} \mathrm{~nm}$ or expressed as Log OD $\mathrm{D}_{50}$. Detecting RBD-

293 specific IgGs against mutated RBDs was carried out in a similar way.

\subsection{Avidity (ELISA)}


bioRxiv preprint doi: https://doi.org/10.1101/2021.12.20.473421; this version posted December 22, 2021. The copyright holder for this preprint (which was not certified by peer review) is the author/funder, who has granted bioRxiv a license to display the preprint in perpetuity. It is made available under aCC-BY 4.0 International license.

295 To test IgG antibody avidity against RBD protein, threefold serial dilutions of 1/20 diluted mice

296 sera, were added to ELISA plates (96 well half-area ELISA plates; Costar, Corning, Catalog

297 \# 3690) coated over night at $4^{\circ} \mathrm{C}$ with $1 \mu \mathrm{g} / \mathrm{ml} \mathrm{RBD}$. After incubation at $\mathrm{RT}$ for $1 \mathrm{~h}$, the plates

298 were washed once in PBS-0.01\% Tween, and then washed $3 x$ with $7 \mathrm{M}$ urea in PBS-

$2990.05 \%$ Tween or with PBS-0.05\% Tween for $5 \mathrm{~min}$ every time. After washing with PBS-

$300 \quad 0.05 \%$ Tween, goat anti-mouse IgG conjugated to Horseradish Peroxidase (HRP) (Jackson

301 ImmunoResearch, West Grove, Pennsylvania) was added 1/1000 and incubated for $1 \mathrm{~h}$ at RT.

302 Plates were developed and read at $\mathrm{OD}_{450} \mathrm{~nm}$.

303 4.7. Cytopathic effect-based neutralization assay (CPE)

304 To determine the neutralizing ability and capacity of vaccine induced antibodies a CPE assay

305 was performed using wild-type SARS-CoV-2 (SARS-CoV-2/ABS/NL20) and delta Strain.

306 Serum samples were heat-inactivated for $30 \mathrm{~min}$ at $56^{\circ} \mathrm{C}$. Two-fold serial dilutions were

307 prepared starting at 1:20 up to 1:160. $100 \mathrm{TCID}_{50}$ of the virus was added to each well and

308 incubated for $37^{\circ} \mathrm{C}$ for $1 \mathrm{~h}$. The mixture has been added on a monolayer of Vero cells and

309 incubated again for $37^{\circ} \mathrm{C}$ for 4 days. Four days later the cells were inspected for cytopathic

310 effect. The titer was expressed as the highest dilution that fully inhibits formation of CPE.

311 4.8. Statistical analysis

312 All data are presented as mean \pm SEM. Data were analyzed using Ordinary One-way ANOVA

313 for multiple comparisons and Students' t-test when comparing two groups. At least two

314 independent experiments were performed. Statistical significance was set at $p \leq 0.05 .{ }^{*} P<0.05$,

$315{ }^{* *} \mathrm{P}<0.01,{ }^{* * *} \mathrm{P}<0.001,{ }^{* * *} \mathrm{P}<0.0001$. Analyses were performed using GraphPad PRISM 9.0

316 (Graph-Pad Software, Inc., La Jolla, CA, USA).

317 


\section{ACKNOWLEDGMENT}

319 This work was supported by Saiba AG and Inselspital Bern.

320

\section{CONFLICT OF INTEREST}

322 M. F. Bachmann is a board member of Saiba AG and holds the patent of CuMV $\mathrm{TT}^{-\mathrm{VLPS} .}$ M.

323 Mohsen received payments by Saiba AG to work on the development of vaccines. M. F.

324 Bachmann and M. O. Mohsen are shareholder of Saiba AG.

325

\section{AUTHORS' CONTRIBUTIONS}

327 ASV, LJ, PSK, XC, AZ, MOM, MFB: Design of experiments, acquisition of data, interpretation,

328 and analysis of data. ASV, MOM, MV, MFB: Writing, revision, and editing of manuscript. LJ,

329 MV, AZ: Technical, material, and tool support. MOM and MFB: Study supervision. All authors

330 read and approved the final manuscript.

\section{DATA AVAILABILITY STATEMENT}

333 The datasets generated during and/or analyzed during the current study are available from

334 the corresponding author on reasonable request. 


\section{References:}

338 1. Liang JL, Tiwari T, Moro P, Messonnier NE, Reingold A, Sawyer M, et al. Prevention

339 of Pertussis, Tetanus, and Diphtheria with Vaccines in the United States: Recommendations

340 of the Advisory Committee on Immunization Practices (ACIP). MMWR Recomm Rep.

$341 \quad 2018 ; 67(2): 1-44$.

342 2. Lu S. Heterologous prime-boost vaccination. Curr Opin Immunol. 2009;21(3):346-51.

343 3. Kent SJ, Zhao A, Best SJ, Chandler JD, Boyle DB, Ramshaw IA. Enhanced T-cell

344 immunogenicity and protective efficacy of a human immunodeficiency virus type 1 vaccine

345 regimen consisting of consecutive priming with DNA and boosting with recombinant fowlpox 346 virus. J Virol. 1998;72(12):10180-8.

347 4. Schneider J, Gilbert SC, Blanchard TJ, Hanke T, Robson KJ, Hannan CM, et al.

348 Enhanced immunogenicity for CD8+ T cell induction and complete protective efficacy of 349 malaria DNA vaccination by boosting with modified vaccinia virus Ankara. Nat Med. 350 1998;4(4):397-402.

351 5. Da Silva DM, Pastrana DV, Schiller JT, Kast WM. Effect of preexisting neutralizing 352 antibodies on the anti-tumor immune response induced by chimeric human papillomavirus 353 virus-like particle vaccines. Virology. 2001;290(2):350-60.

354 6. Keller SA, Schwarz K, Manolova V, von Allmen CE, Kinzler MG, Bauer M, et al. Innate 355 signaling regulates cross-priming at the level of DC licensing and not antigen presentation. 356 Eur J Immunol. 2010;40(1):103-12.

357 7. Skowronski DM, De Serres G. Safety and Efficacy of the BNT162b2 mRNA Covid-19 358 Vaccine. N Engl J Med. 2021;384(16):1576-7.

359 8. He Q, Mao Q, An C, Zhang J, Gao F, Bian L, et al. Heterologous prime-boost: breaking 360 the protective immune response bottleneck of COVID-19 vaccine candidates. Emerg Microbes 361 Infect. 2021;10(1):629-37.

362 9. Baden LR, El Sahly HM, Essink B, Kotloff K, Frey S, Novak R, et al. Efficacy and Safety 363 of the mRNA-1273 SARS-CoV-2 Vaccine. N Engl J Med. 2021;384(5):403-16.

364 10. Polack FP, Thomas SJ, Kitchin N, Absalon J, Gurtman A, Lockhart S, et al. Safety and 365 Efficacy of the BNT162b2 mRNA Covid-19 Vaccine. N Engl J Med. 2020;383(27):2603-15.

366 11. He Q, Mao Q, Zhang J, Bian L, Gao F, Wang J, et al. COVID-19 Vaccines: Current 367 Understanding on Immunogenicity, Safety, and Further Considerations. Front Immunol. 368 2021;12:669339.

369 12. Nooraei S, Bahrulolum H, Hoseini ZS, Katalani C, Hajizade A, Easton AJ, et al. Virus370 like particles: preparation, immunogenicity and their roles as nanovaccines and drug 371 nanocarriers. J Nanobiotechnology. 2021;19(1):59. 
372 13. Mohsen MO, Zha L, Cabral-Miranda G, Bachmann MF. Major findings and recent 373 advances in virus-like particle (VLP)-based vaccines. Semin Immunol. 2017;34:123-32.

374 14. Karandikar SM, A.; Waybhase, V.; Patravale, V.; Patankar, S.;. Micro and Nano 375 Technologies. Ecaterina Andronescu AMG, editor: Elsevier; 2017.

376 15. Mohsen MO, Balke I, Zinkhan S, Zeltina V, Liu XL, Chang XY, et al. A scalable and 377 highly immunogenic virus-like particle-based vaccine against SARS-CoV-2. Allergy. 2021.

378 16. Chang X, Zeltins A, Mohsen MO, Gharailoo Z, Zha L, Liu X, et al. A Novel Double 379 Mosaic Virus-like Particle-Based Vaccine against SARS-CoV-2 Incorporates Both Receptor 380 Binding Motif (RBM) and Fusion Domain. Vaccines (Basel). 2021;9(11).

381 17. Zhang NN, Li XF, Deng YQ, Zhao H, Huang YJ, Yang G, et al. A Thermostable mRNA 382 Vaccine against COVID-19. Cell. 2020;182(5):1271-83 e16.

383 18. Anand P, Stahel VP. Review the safety of Covid-19 mRNA vaccines: a review. Patient 384 Saf Surg. 2021;15(1):20.

385 19. Van Lint S, Heirman C, Thielemans K, Breckpot K. mRNA: From a chemical blueprint 386 for protein production to an off-the-shelf therapeutic. Hum Vaccin Immunother. 2013;9(2):26538774.

388 20. Mohsen MO, Rothen D, Balke I, Martina B, Zeltina V, Inchakalody V, et al. 389 Neutralization of MERS coronavirus through a scalable nanoparticle vaccine. Npj Vaccines. $390 \quad 2021 ; 6(1)$.

391 21. Zeltins A, West J, Zabel F, El Turabi A, Balke I, Haas S, et al. Incorporation of tetanus392 epitope into virus-like particles achieves vaccine responses even in older recipients in models 393 of psoriasis, Alzheimer's and cat allergy. NPJ Vaccines. 2017;2:30.

394 22. Augusto G, Mohsen MO, Zinkhan S, Liu XL, Vogel M, Bachmann MF. In vitro data 395 suggest that Indian delta variant B.1.617 of SARS-CoV-2 escapes neutralization by both 396 receptor affinity and immune evasion. Allergy. 2021.

397 23. Puranik A, Lenehan PJ, Silvert E, Niesen MJM, Corchado-Garcia J, O'Horo JC, et al. 398 Comparison of two highly-effective mRNA vaccines for COVID-19 during periods of Alpha and 399 Delta variant prevalence. medRxiv. 2021.

400 24. Crommelin DJA, Anchordoquy TJ, Volkin DB, Jiskoot W, Mastrobattista E. Addressing 401 the Cold Reality of mRNA Vaccine Stability. J Pharm Sci. 2021;110(3):997-1001.

402 25. Information for healthcare professionals on pfizer BioNTech COVID-19 vaccine. UK 403 department of Health and social care2020.

404 26. Meo SA, Bukhari IA, Akram J, Meo AS, Klonoff DC. COVID-19 vaccines: comparison 405 of biological, pharmacological characteristics and adverse effects of Pfizer/BioNTech and 406 Moderna Vaccines. Eur Rev Med Pharmacol Sci. 2021;25(3):1663-9. 
bioRxiv preprint doi: https://doi.org/10.1101/2021.12.20.473421; this version posted December $22,2021$. The copyright holder for this preprint (which was not certified by peer review) is the author/funder, who has granted bioRxiv a license to display the preprint in perpetuity. It is made available under aCC-BY 4.0 International license.

407 27. Lynch A, Meyers AE, Williamson AL, Rybicki EP. Stability studies of HIV-1 Pr55(gag)

408 virus-like particles made in insect cells after storage in various formulation media. Virology

409 Journal. 2012;9.

410 28. Bachmann MF, Mohsen MO, Zha LS, Vogel M, Speiser DE. SARS-CoV-2 structural

411 features may explain limited neutralizing-antibody responses. Npj Vaccines. 2021;6(1).

412

413 


\section{6. Figures legends:}

415 Figure 1. Heterologous prime-boost vaccine administration induces comparable high

416 levels of RBD-specific antibodies following the booster dose

417 Heterologous prime boost vaccination induces high levels of RBD-specific antibodies. A)

418 Vaccination regiment (Prime/Boost) D0/D21 and groups. B-D) OD 450 of RBD-specific IgG for

419 the groups vaccinated with mRNA-1723 or mCuMV TT $-R B M$ on days 7,14 and 21 . E-G)

$420 \log _{10} \mathrm{OD}_{50}$ of RBD-specific IgG titers for the groups vaccinated with mRNA-1723 or mCuMV $\mathrm{TT}^{-}$

421 RBM on days 7, 14 and 21. H-J) $\mathrm{OD}_{450}$ of RBD-specific IgG for the groups boosted with mRNA-

4221723 or $\mathrm{mCuMV}_{\mathrm{TT}}-\mathrm{RBM}$ on days 28,35 and $\left.42 . \mathrm{K}\right) \log _{10} \mathrm{OD}_{50}$ of RBD-specific IgG titers for

423 the groups boosted with mRNA-1723 or mCuMV $\mathrm{TT}_{\mathrm{T}}-\mathrm{RBM}$ on days 28,35 and 42 using D0/D21

424 regimen. Statistical analysis (mean \pm SEM) using one- way ANOVA in K or Student's $t$ test in

425 E-G, $n=10$ or 5 . One representative of 3 similar experiments is shown. The value of $p<0.05$

was considered statistically significant $\left({ }^{*} p<0.01,{ }^{* *} p<0.001,{ }^{* * *} p<0.0001\right)$.

Figure 2. A second booster dose further enhances the induced immune response

429 Enhanced immune response with second booster dose. A) Vaccination regiment (Prime-

430 Boost-Boost) D0/D21/D56 and groups. B and C) $\mathrm{OD}_{450}$ of RBD-specific IgG for the groups

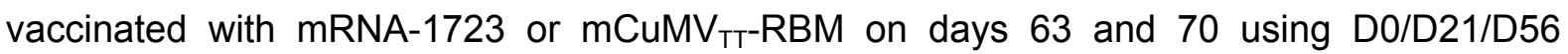
regimen. $\mathrm{D}$ and $\mathrm{E}) \mathrm{Log}_{10} \mathrm{OD}_{50}$ of $\mathrm{RBD}$-specific IgG titers for the groups vaccinated with mRNA1723 or $\mathrm{mCuMV}_{\mathrm{TT}}-\mathrm{RBM}$ on 63 and 70 using D0/D21/D56 regimen. F) Avidity Index of RBDspecific $\lg$ in mice vaccinated with mRNA-1723 or mCuMV $\mathrm{TT}^{-}$RBM using D0/D21 or D0/D21/D56 regimens, sera were treated with PBST or $7 \mathrm{M}$ Urea. G) $\mathrm{OD}_{450}$ of RBD-specific 436 longeivity IgG for the groups vaccinated with mRNA-1723 or mCuMV $\mathrm{TT}_{\mathrm{T}}-\mathrm{RBM} 5$ months after 437 priming using D0/D21/D56 regimen. $H$ ) $\log _{10} \mathrm{OD}_{50}$ of RBD-specific IgG titers for the groups 438 vaccinated with mRNA-1723 or $\mathrm{mCuMV}_{\mathrm{TT}}-\mathrm{RBM} 5$ month after priming, using D0/D21/D56 regimen. Statistical analysis (mean \pm SEM) using one- way ANOVA in D,E and H or Student's

$440 \mathrm{t}$ test in $\mathrm{F}, \mathrm{n}=10$ or 5 . One representative of 3 similar experiments is shown. The value of $441{ }^{*} p<0.05$ was considered statistically significant $\left({ }^{* *} p<0.01\right)$. 
442 Figure 3. The induced antibodies recognize SARS-CoV-2 variants of concern (VoCs) 443 efficiently

444 Recognition of SARS-CoV-2 variants of concern. A and B) Neutralization titer (CPE) for sera

445 from mice vaccinated with $\mathrm{mRNA}-1723$ and mice vaccinated with $\mathrm{mCuMV} \mathrm{TT}_{\mathrm{T}}-\mathrm{RBM}$, sera from

446 day 63 (after 2nd boost). Statistical analysis (mean \pm SEM) using ANOVA, $n=5$. One

447 representative of 2 similar experiments is shown. The value of ${ }^{*} p<0.05$ was considered

448 statistically significant $\left({ }^{* *} p<0.01,{ }^{* * *} p<0.001,{ }^{* * *} p<0.0001\right)$.

449 
A.

Prime Do

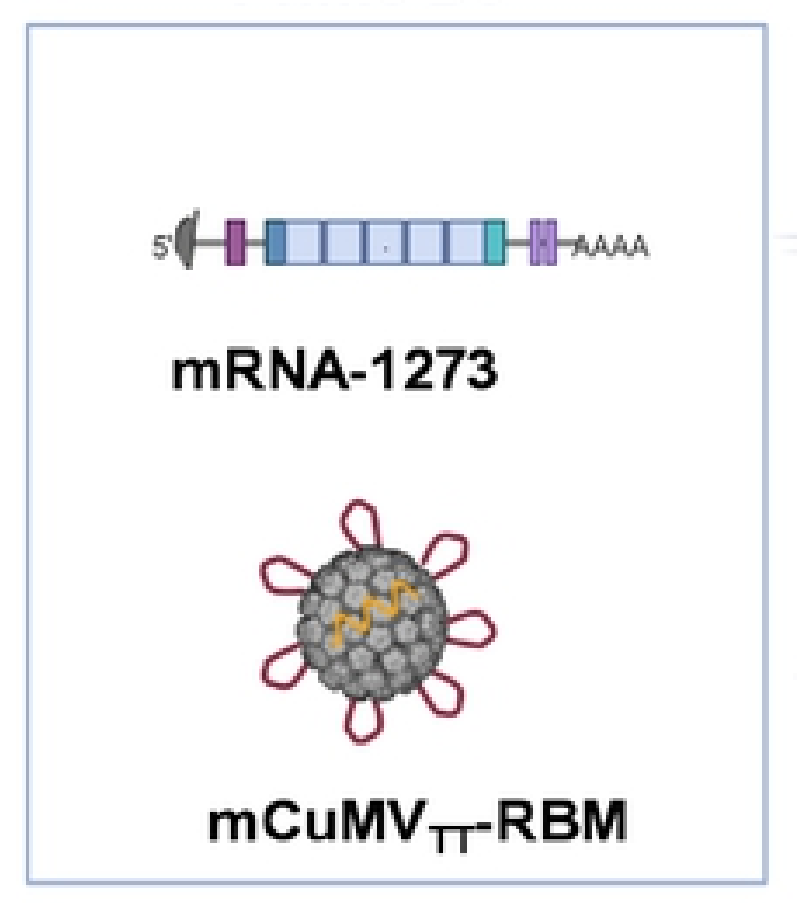

$1^{\text {st }}$ Boost D21

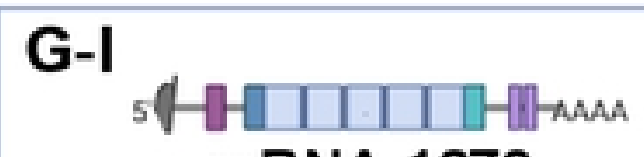

mRNA-1273

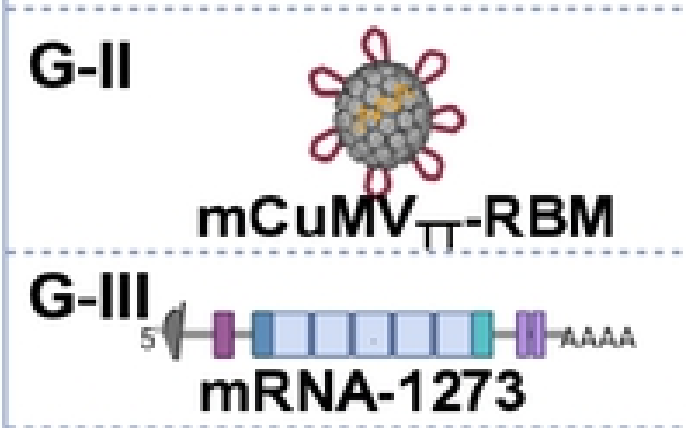

G-IV

mCuMV $V_{T T}$ RBM
B.

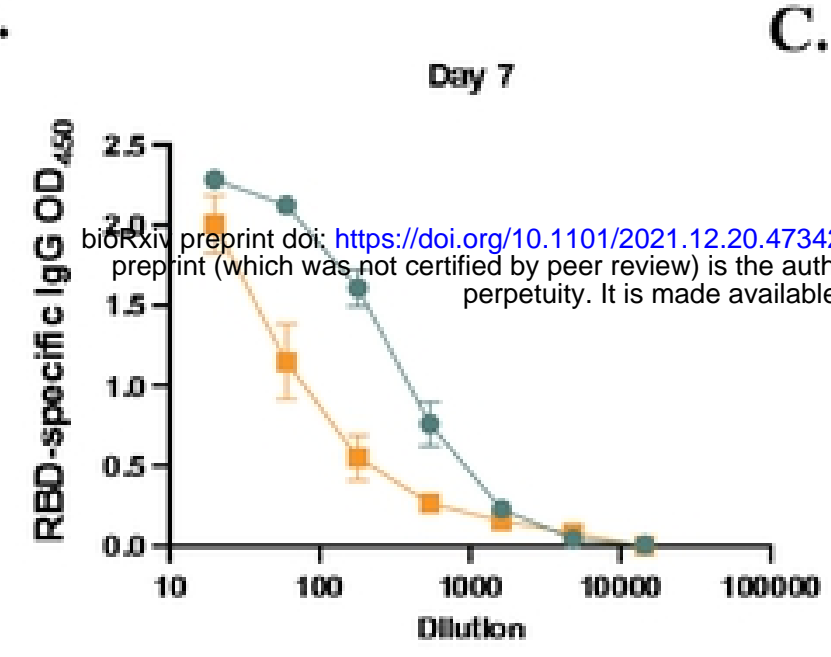

E.

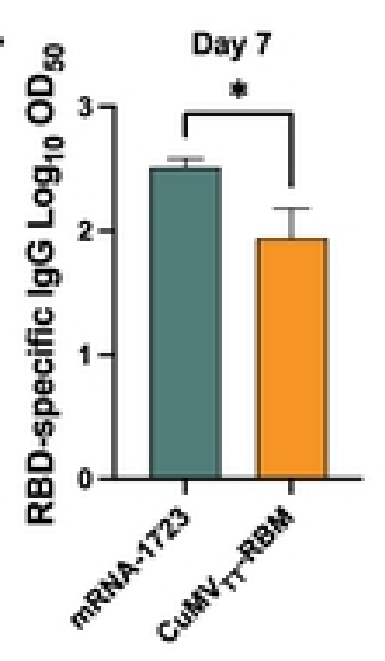

C.

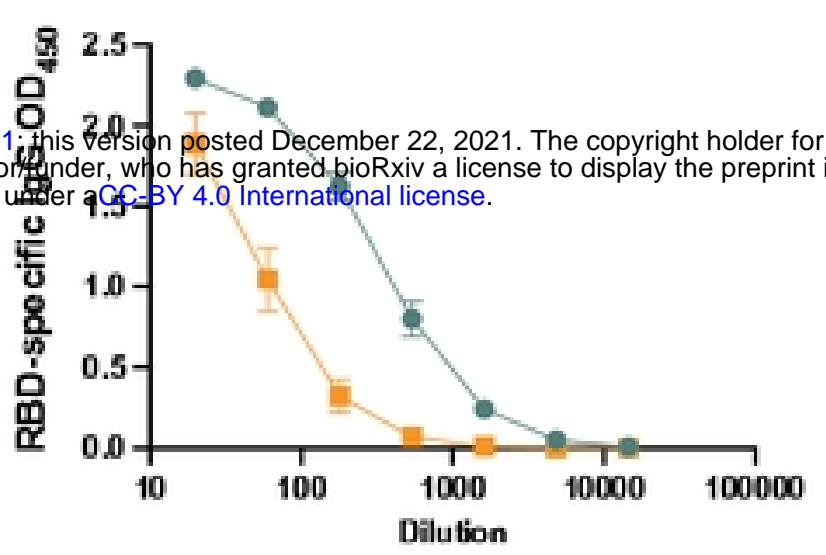

F.

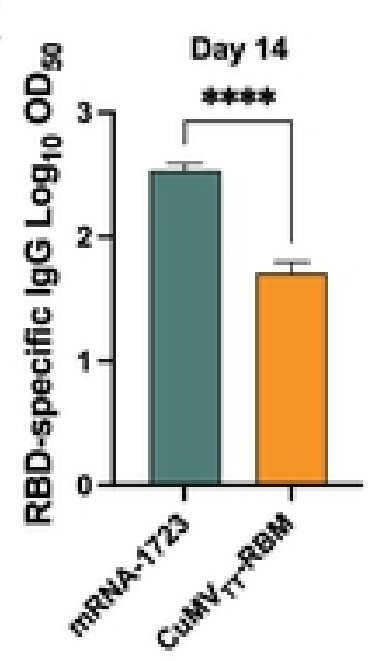

D.

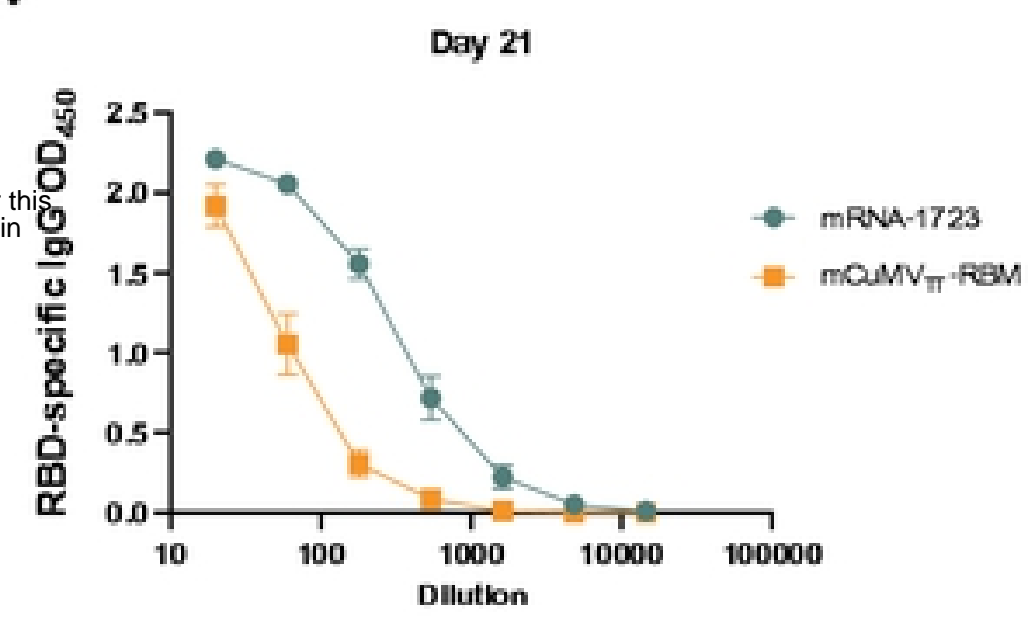

G.

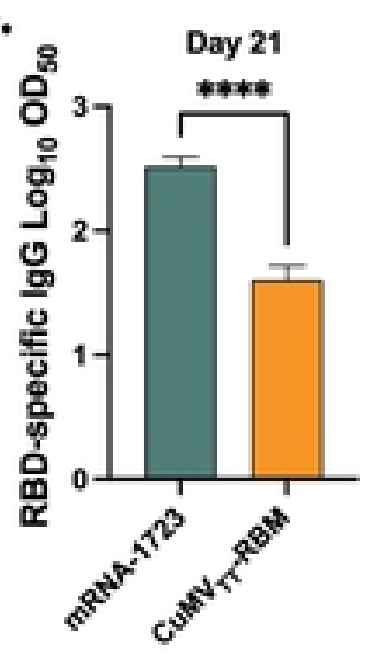

H.

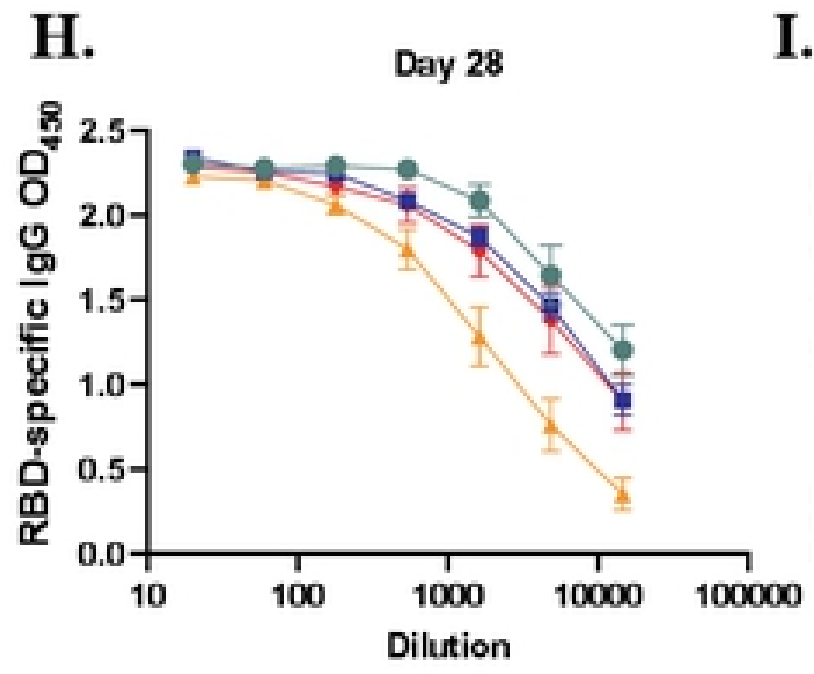

I.

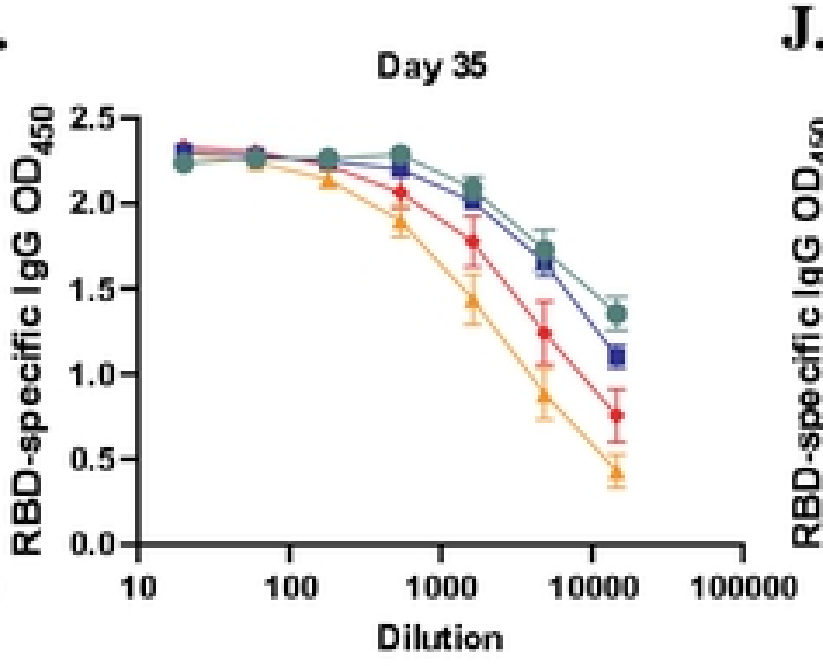

J.

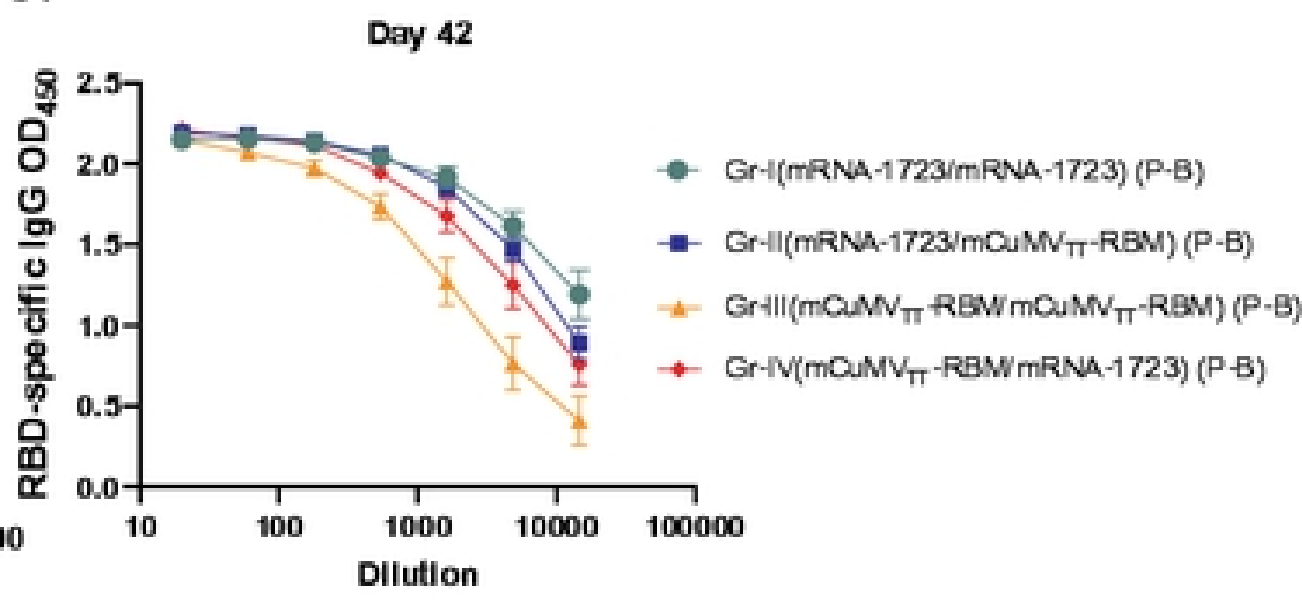

K.

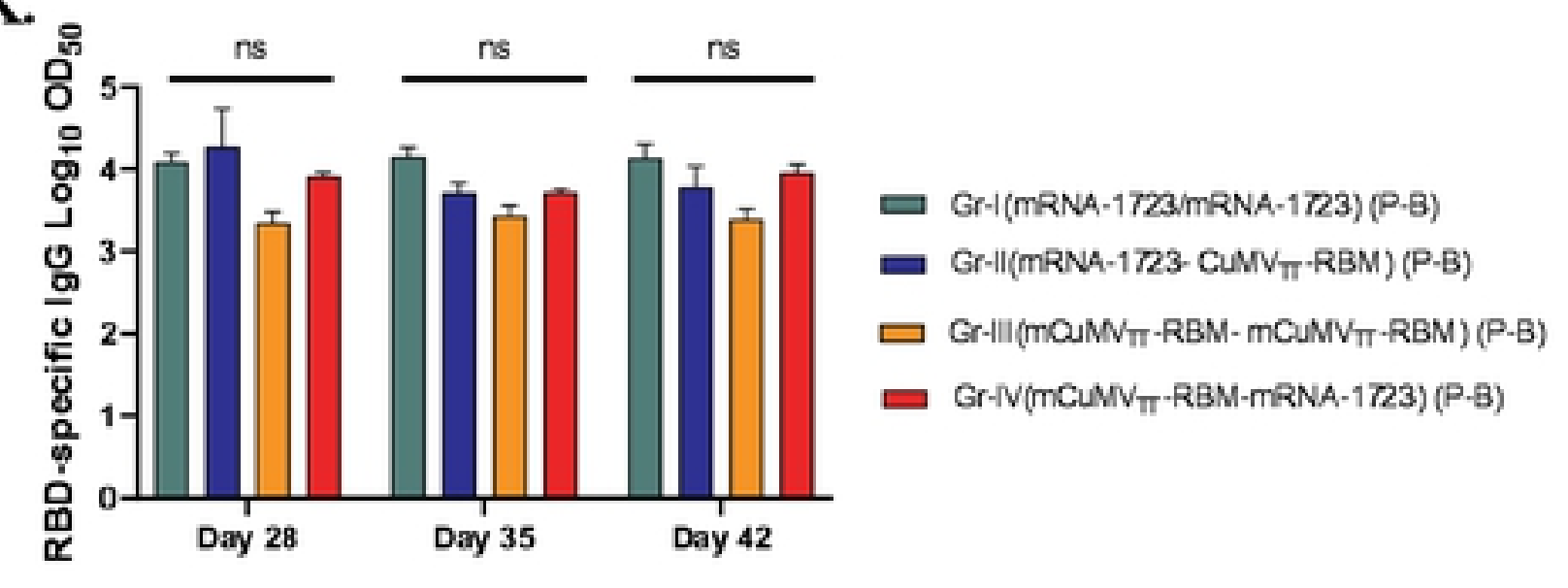

Figure 1 
Wuhan Variant

*****
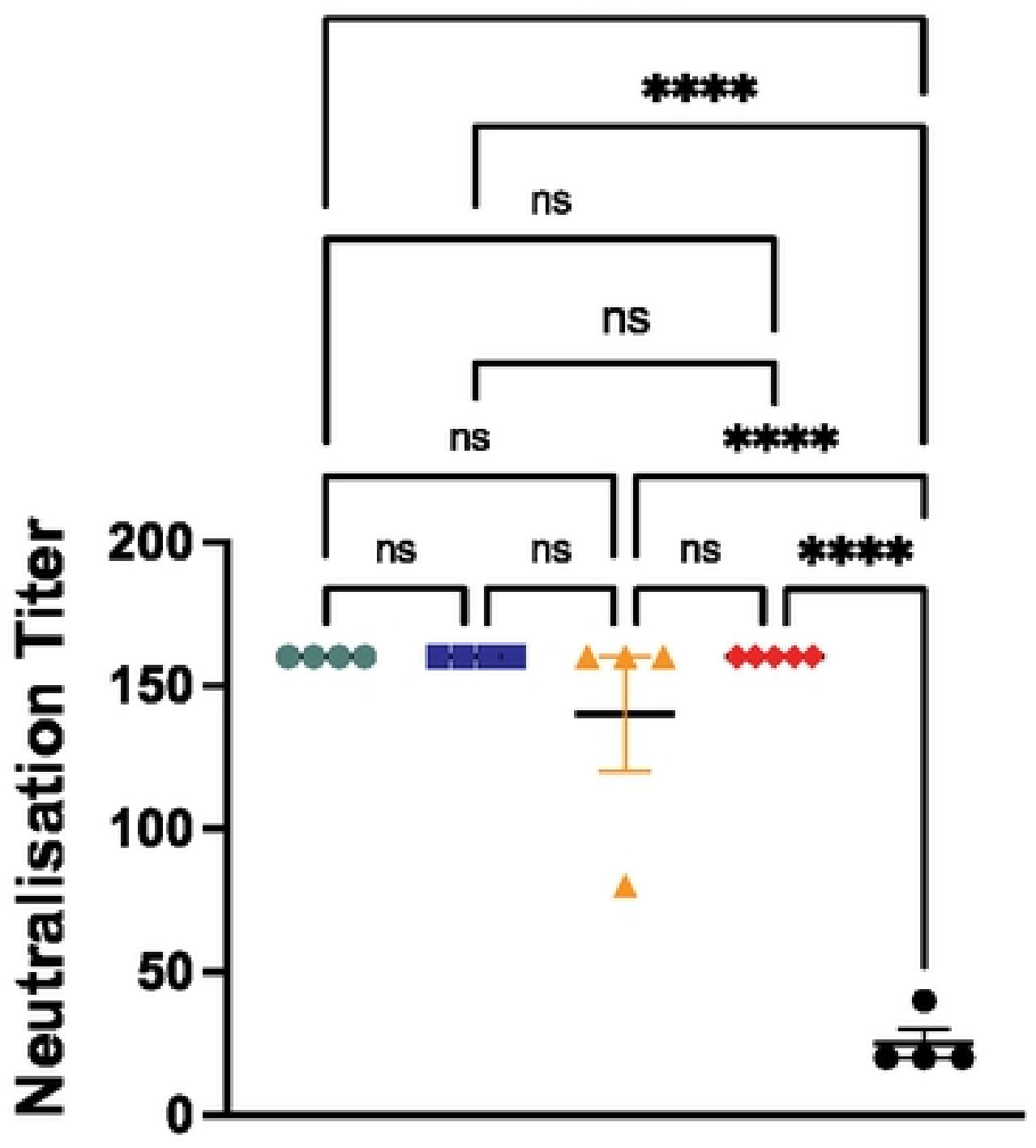

Delta Variant

*****
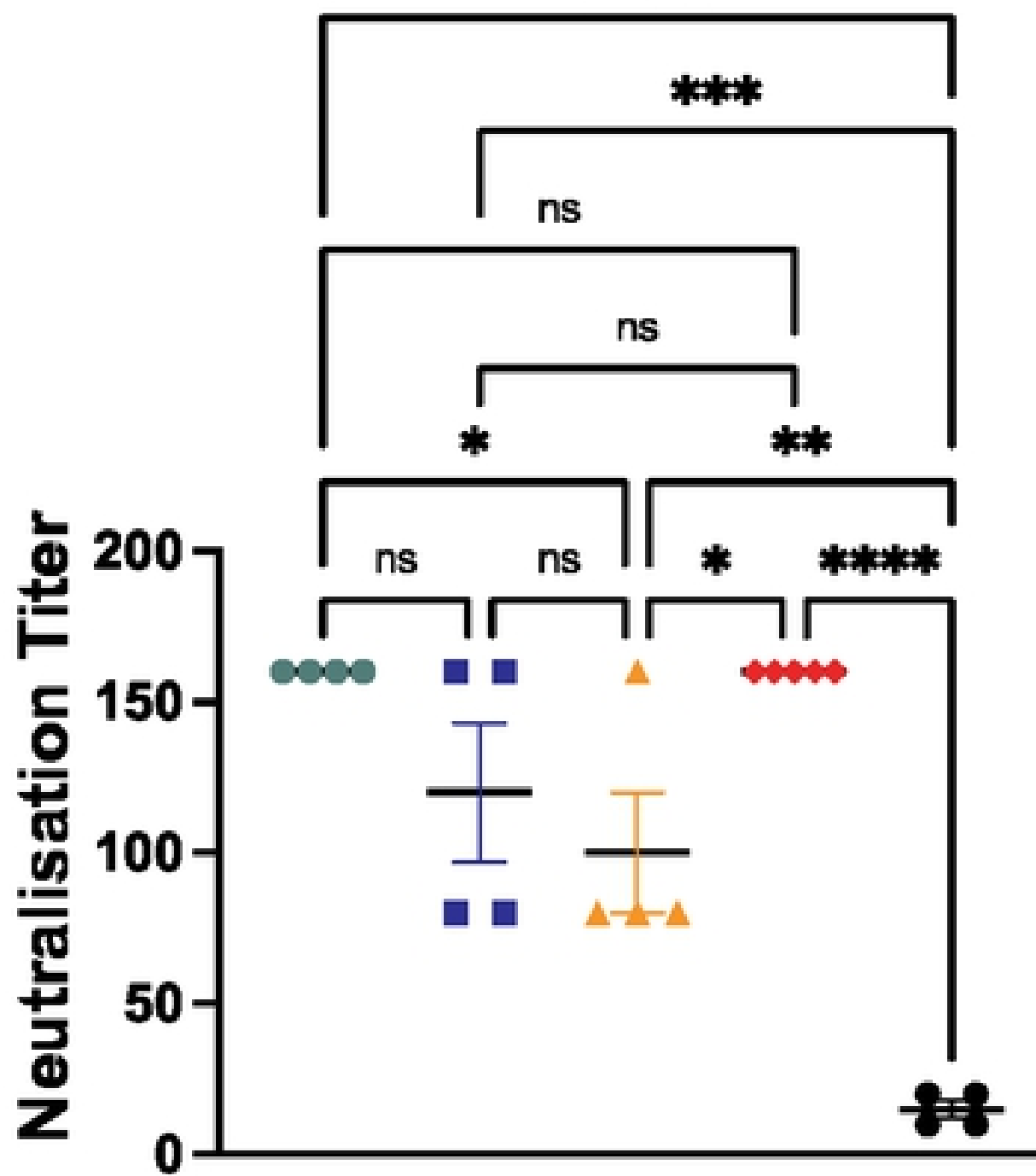

$\square$ Gr-I(mRNA-1723/mRNA-1723-0) (P-B-0)

$\square$ Gr-II(mRNA-1723/mCuMV $\left.{ }_{T T}-R B M / m C u M V V_{T T}-R B M\right)(P-B-B)$

$\square \mathrm{Gr}-\mathrm{II}\left(\mathrm{mCuMV} \mathrm{TT}_{\mathrm{T}}-\mathrm{RBM} / \mathrm{mCuMV} \mathrm{TT}_{\mathrm{T}}-\mathrm{RBM} / \mathrm{mCuMV} \mathrm{TT}_{\mathrm{T}}-\mathrm{RBM}\right)(\mathrm{P}-\mathrm{B}-\mathrm{B})$

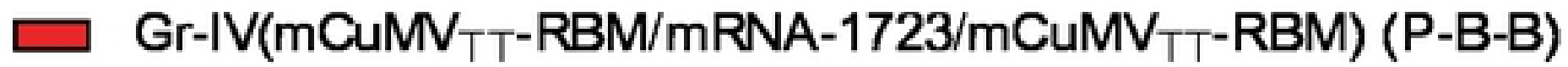

naive

Figure 3 